\title{
Corticotomy for Correction of Skeletal Anterior Open Bite Using Miniplates as Skeletal Anchorage (A Clinical and Cone Beam Comparative Study)
}

\author{
Maha M. Mohamed ${ }^{(1)}$, Ahmed E. Salama ${ }^{(2)}$, Tarek H. Marei ${ }^{(3)}$, Hatem H. Alahmady ${ }^{(4)}$ \\ and Farouk A. Hussain ${ }^{(5)}$
}

Codex : 49/1710

dentaljournal.forgirls@yahoo.com

\section{KEYWORDS}

Corticotomy, skeletal open bite, intrusion, miniplates.

\begin{abstract}
Objective: This study was designed to evaluate the effect of corticotomy and miniplates' usage as skeletal anchorage for maxillary molars' intrusion during correction of skeletal anterior open bite (SAOB). Patients, materials and methods: A sample of 22 patients with an age range from 14 to 22 years, suffering from skeletal anterior open bite with increased posterior maxillary vertical height. The participants were randomly divided into two groups according to the corticotomy approach. Group I: both buccal and palatal corticotomies were performed. Group II: only buccal corticotomy was performed. Buccal miniplates and palatal mini-screws were used as skeletal anchorage for maxillary molars' intrusion assisted by corticotomy. The measurements, including maxillary dento-alveolar heights $(\mathrm{mm})$, bucal crestal alveolar bone heights $(\mathrm{mm})$, bucco-palatal angulations $\left(\mathrm{B}-\mathrm{P}^{\circ}\right)$ and mesio-distal angulations $\left(\mathrm{M}-\mathrm{D}^{\circ}\right)$ of right and left maxillary first permanent molars, 4.5 months after intrusion commencement. Results: The dento-alveolar height as well as the buccal crestal alveolar height decreased significantly after intrusion in both groups $(p \leq 0.001$ and $\mathrm{p} \leq 0.05$, respectively), but without significant differences between them. Similarly, the M-D and B-P angulations increased significantly after intrusion in both groups ( $\mathrm{p} \leq 0.01$ and $\mathrm{p} \leq 0.001$, respectively), with no significant differences between both groups Conclusions: The current corticotomy approaches and temporary anchorage devices (TADs) were similarly effective for maxillary molar intrusion in cases of (SAOB), but complete correction of SAOB was not achieved. Both the posterior maxillary dento-alveolar and buccal crestal alveolar bone heights diminished similarly in both corticotomy methods. Neither mesio-distal nor bucco-palatal angulations of maxillary first permanent molar crown revealed major changes in matching both approaches of intrusion.
\end{abstract}

- Paper extracted from Ph.D thesis entitled "Corticotomy for Correction of Skeletal Anterior Open Bite Using Miniplates as Skeletal Anchorage (A Clinical and Cone Beam Comparative Study).

1. Assistant Lecturer of Orthodontics, Orthodontic Department, Faculty of Dental Medicine for Girls, Al- Azhar University.

2. Professor of Orthodontics, Orthodontic Department, Faculty of Dental Medicine for Girls, Al-Azhar University.

3. Assistant Professor of Orthodontics, Orthodontic Department, Faculty of Dental Medicine for Girls, Al-Azhar University.

4. Professor of Oral and Maxillo-facial Surgery, Faculty of Dental Medicine, Faculty of Dental Medicine for Girls, Al-Azhar University.

5. Assistant Professor of Orthodontics, Orthodontic Department, Faculty of Dental Medicine, Al-Azhar University (Boy's branch). 


\section{INTRODUCTION}

Skeletal anterior open bite is one of the most difficult cases in orthodontics not only to treat, but also to retain due to its multifactorial nature. In adult patients, treatment of severe skeletal anterior open bite consists mainly of surgically repositioning both the maxilla and the mandible. This is true in the adult because adults have little growth potential, and often open bites are combined with a long face tendency ${ }^{(1-3)}$. Many treatment modalities were proposed for such cases like high pull head gear, as well as, intra- oral appliances such as Harvold activator, open bite bionator, posterior bite blocks, as intrusive modalities whereby successful molar intrusion was achieved in an attempt to correct SOB. Unfortunately, however, these techniques have a number of other demerits ${ }^{(4-9)}$.

Noteworthy, surgical treatment of SOB malocclusion by conventional Le Fort 1 surgery was considered as the typical treatment or the first option for SAOB malocclusions ${ }^{(10)}$. Unfortunately, patient acceptance of this treatment modality was almost negative and not accepted by most of the current research patients. The second treatment option was intrusion of the posterior teeth to correct the anterior open bite. Therefore, molar intrusion considered to be the best treatment choice because it leads to an autorotation of the mandible in the counterclockwise direction, thus improving the long anterior facial height ${ }^{(11,12)}$. However, there might be other, less-invasive treatment options not requiring orthognathic surgery. If it is possible to orthodontically intrude posterior teeth, the accompanying changes in occlusal plane, mandibular plane, lower anterior face height, and anterior dental overbite would close the patient's open bite. However, intrusion of posterior or anterior dentition is always difficult to achieve without the side effect of extrusion of the anchorage teeth ${ }^{(10-17)}$.

The temporary anchorage devices (TADs), such as dental implants ${ }^{(14,18-20)}$, miniplates ${ }^{(15,21-25)}$, and mini-screws ${ }^{(16,23,26-28)}$ have been developed in a trial to provide the solution of this problem, i.e. extrusion of anchorage teeth. Based on the above mentioned reports, the present study aimed to correct SAOB malocclusion by posterior maxillary intrusion via buccal miniplates and palatal mini-screws. This approach was assisted by corticotomies to reduce the resistance of the cortical bone and to shorten the required intrusion time. Additionally, corticotomy assisted intrusion could decrease the chance of hazards that could occur with intrusive tooth movement, such as root resorption and loss of tooth vitality especially in adult patients ${ }^{(13,21,22,29-31)}$. Cone beam computed tomography (CBCT) was used for evaluation of the intrusion due to the proposed limitations of the two dimensional radiographic assessments ${ }^{(32-34)}$. Therefore, the current CBCT study aimed to evaluate and compare the effect of maxillary molar intrusion via miniplates and mini-screws in correction of SAOB cases that was assisted with buccal side corticotomies with or without a palatal one.

\section{PATIENTS, MATERIALS AND METHODS}

The present clinical study was conducted initially on 22 patients with age range between 1422 years old with increased posterior maxillary dento-alveolar height. The participants were randomly divided into two groups according to the corticotomy undertaken in the posterior maxillary segment; each consisted initially of 11 patients. In group (I) both buccal and palatal corticotomies were performed, and group (II) only buccal corticotomy was assumed. Additionally, in both groups, buccal miniplates and palatal mini-screws were used as TADs to provide palatal intrusive force in both right and left maxillary molars which were leveled and aligned with maxillary premolars using segmental fixed orthodontic appliance (Unitek ${ }^{\mathrm{TM}}$ Metal bands, 3M Unitek USA, Unitek ${ }^{\mathrm{TM}}$ Miniature Twin Metal Brackets, 3M, Unitek USA, Unitek ${ }^{\mathrm{TM}}$ Orthodontic Composite, 3M, Unitek USA). Sequential orthodontic arch wires were used starting from 0.012 " Ni-Ti up to $0.016 \times 0.022$ " St.St. arch wire (G \& H wire company, USA). 
The patients and/or guardians were fully informed about the procedures, and informed written consents were obtained before commencing the study and approved by the Ethical Committee of Faculty of Dental Medicine for Girls, Al-Azhar University, Cairo, Egypt.

The following routine orthodontic records were obtained for each patient before treatment:

1. Extra-oral photographs (frontal at rest, frontal during smile, right and left profile views).

2. Intra-oral photographs (frontal, right and left side views, upper and lower occlusal views).

3. Orthodontic study models.

4. Standardized lateral cephalometric radiographs.

5. Panoramic radiograph.

In addition, pre-and post-intrusion CBCT images were obtained after an average observation period of 4.5 months and the following CBCT measurements were evaluated before intrusion (T1) and after intrusion (T2):

1- Dento-alveolar height $(\mathrm{mm})$ of right and left maxillary first permanent molars.

2- Buccal crestal alveolar bone height $(\mathrm{mm})$ of right and left maxillary first permanent molars.

3- Mesio-distal angulation ( ${ }^{\circ}$ ) of right and left maxillary first permanent molars.

4- Bucco-palatal angulation $\left({ }^{\circ}\right)$ of right and left maxillary first permanent molars.

Unfortunately, 9 patients were dropped out from the current study ( 5 from group I, and 4 from group II). This was mainly due to lack of patient compliance and co-operation and the failure to communicate with most of them after performing the surgical procedures. Additionally, it was very difficult to compensate for dropped out patients due to the relatively low prevalence and nature of this complex malocclusion. Therefore, the study objectives were evaluated with the remaining 13 patients.

The collected data were tabulated and statistically analyzed for each variable within each group using
Statistical Package for Social Science (SPSS) Version 20. Comparison of the changes in the previous measurements between groups, as well as within each group, were performed using student's $\mathrm{t}$ - test, paired t-test for parametric measures, and Mann-Whitney U test for non-parametric measures.

\section{RESULTS}

The results of the study showed that the dentoalveolar height of right and left first permanent molars had statistically significant decreases of $1.55 \pm 0.71 \mathrm{~mm}$ and $1.11 \pm 0.71 \mathrm{~mm}$, respectively, in patients with both buccal and palatal corticotomies (groupI).In patients whohad only buccal corticotomy (group II), there were statistically significant decreases of $1.37 \pm 0.39 \mathrm{~mm}$ and $1.50 \pm 0.46 \mathrm{~mm}$ in the right and left sides, respectively. These changes were not significantly different from those of the first group. (Tables 1\&2, Figs. 1\&2)

Regarding the height of buccal crestal alveolar bone, it was reduced in group (I) by means of $0.83 \pm 0.12 \mathrm{~mm}$ and $0.23 \pm 0.10 \mathrm{~mm}$ in right and left sides, respectively. However, in group (II), it revealed mean decreases of $1.25 \pm 0.52 \mathrm{~mm}$ and $1.23 \pm 0.52 \mathrm{~mm}$ in right and left maxillary first permanent molars, respectively. Similarly, these changes were not significantly different from those of the first group. (Tables. 3\&4, Figs. 3\&4)

Concerning the mesio-distal angulations of right and left maxillary first permanent molars, there was statistically significant increase in group I that were $1.26 \pm 0.45^{\circ}$ and $0.78 \pm 0.35^{\circ}$, respectively. Moreover, those in group II had mean increases of $1.04 \pm 0.32^{\circ}$ and $1.21 \pm 0.42^{\circ}$, respectively, which were not significantly different from those of the first group. (Tables. 5\&6, Figs. 5\&6)

The results of bucco-palatal angulations of maxillary first permanent molars in group I showed significant increases of $1.79 \pm 0.74^{\circ}$ and $1.89 \pm 0.64^{\circ}$ in right and left sides, respectively. These angulations were $2.30 \pm 0.35^{\circ}$ and $2.9 \pm 0.52^{\circ}$, respectively, in group II which were comparable with those of the first group. (Tables. 7\&8, Figs. 7\&8) 
Table (1) Comparison of amount of changes of dento-alveolar height ( $\mathrm{mm}$ ) of UR6, between both groups, before (T1) \& after (T2) intrusion, using Student's t-test, and Mann-Whitney U test.

\begin{tabular}{|c|c|c|c|c|c|c|c|c|}
\hline & \multicolumn{2}{|c|}{ Group I $(n=6)$} & \multicolumn{2}{|c|}{ Group II (n=7) } & \multicolumn{2}{|c|}{$95 \% \mathrm{Cl}$ for the difference } & \multirow[b]{2}{*}{ p-value } & \multirow[b]{2}{*}{ Sig } \\
\hline & Mean & $S D$ & Mean & $S D$ & Lower bound & Upper bound & & \\
\hline $\mathrm{T} 1$ & 25.60 & 1.02 & 26.65 & 1.32 & -2.42 & 0.33 & $0.122^{\mathrm{a}}$ & NS \\
\hline $\mathrm{T} 2$ & 24.05 & 0.57 & 25.28 & 1.59 & -2.62 & 2.72 & $0.078^{\mathrm{a}}$ & NS \\
\hline Change & -1.55 & 0.71 & -1.37 & 0.39 & -0.85 & 0.49 & $0.277^{b}$ & NS \\
\hline
\end{tabular}

$S D=$ Standard Deviation, $n=$ number, NS: Non-Significant $p>0.05, a=$ Student's $t$-test,$b=$ Mann-Whitney $U$ test, $p=$ probability level, Sig $=$ Significance .

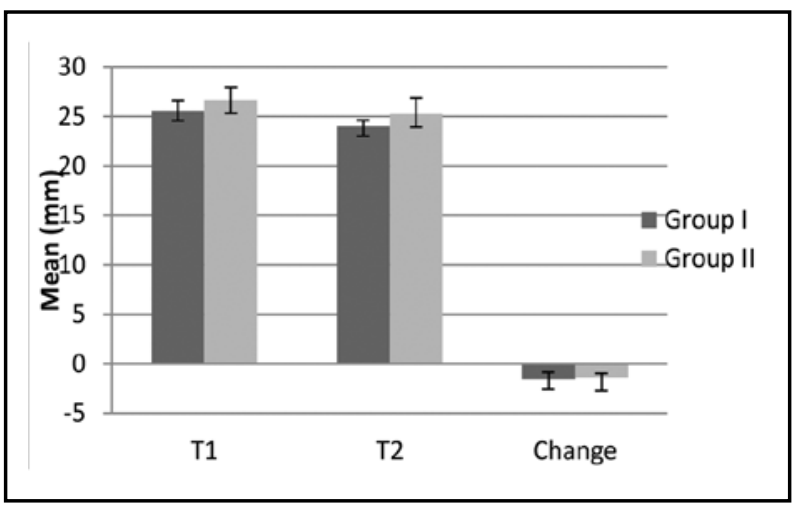

Fig. (1) Bar chart representing comparison of means of dento- alveolar height (mm) of UR6 before (T1) \& after (T2) intrusion between both groups.

Table (2) Comparison of the amount of changes dento-alveolar height ( $\mathrm{mm}$ ) of UL6, between both groups, before (T1) \& after (T2) intrusion, by Student's t-test, and Mann-Whitney U test.

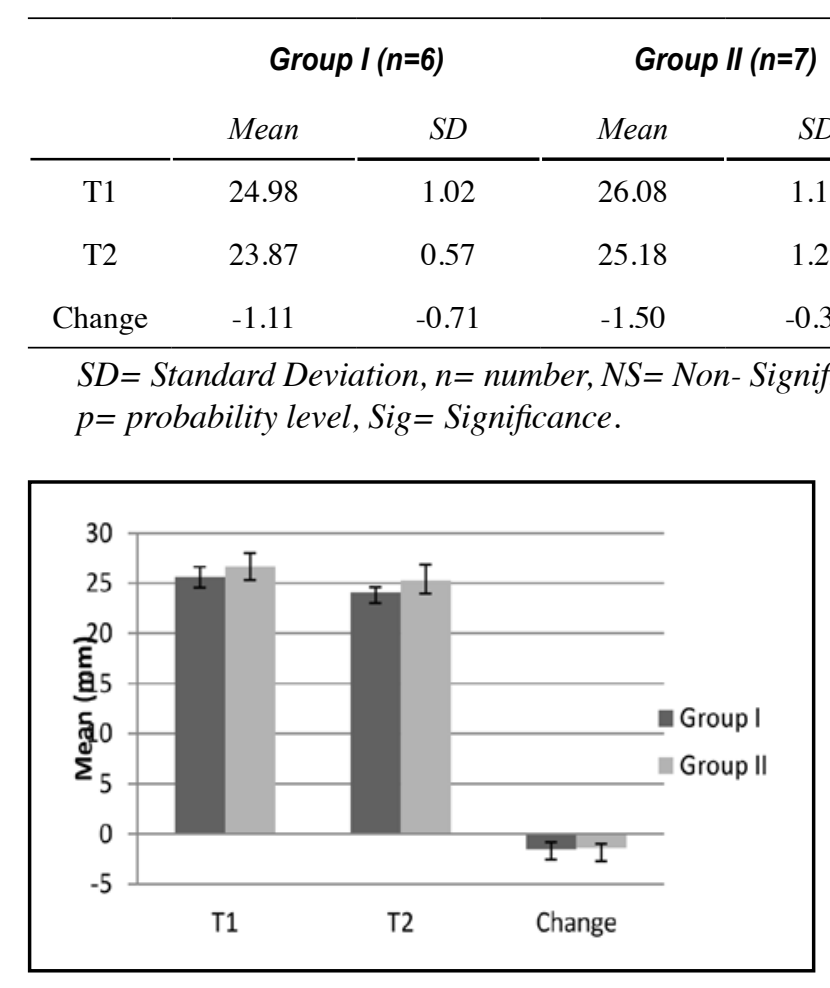

Fig. (2) Bar chart representing means for comparison between dento-alveolar heights ( $\mathrm{mm}$ ) of UL6 between groups. 
Table (3): Comparison between buccal crestal alveolar bone height ( $\mathrm{mm}$ ) of UR6 in both groups before (T1) $\&$ after (T2) intrusion using Student's t-test and Mann-Whitney U test for comparing changes between groups.

\begin{tabular}{|c|c|c|c|c|c|c|c|c|}
\hline & \multicolumn{2}{|c|}{ Group I $(n=6)$} & \multicolumn{2}{|c|}{ Group II (n=7) } & \multicolumn{2}{|c|}{$95 \%$ CI for the difference } & \multirow[b]{2}{*}{$p$-value } & \multirow[b]{2}{*}{ Sig. } \\
\hline & Mean & $S D$ & Mean & $S D$ & Lower bound & Upper bound & & \\
\hline $\mathrm{T} 1$ & 12.93 & 0.83 & 14.09 & 1.01 & -2.24 & -0.8 & $0.037^{\mathrm{a}}$ & $*$ \\
\hline $\mathrm{T} 2$ & 12.10 & 0.89 & 12.84 & 1.05 & -1.87 & 0.40 & $0.183^{\mathrm{a}}$ & NS \\
\hline Change & -0.83 & 0.12 & -1.25 & 0.52 & -0.01 & 0.86 & $0.096^{\mathrm{b}}$ & NS \\
\hline
\end{tabular}

$S D=$ Standard Deviation, $n=$ number, $*=$ Significant $p \leq 0.05, N S=$ Non-Significant, $a=$ Student's t-test, $b=$ Mann- Whitney U test, $p=$ probability level, Sig= Significance.

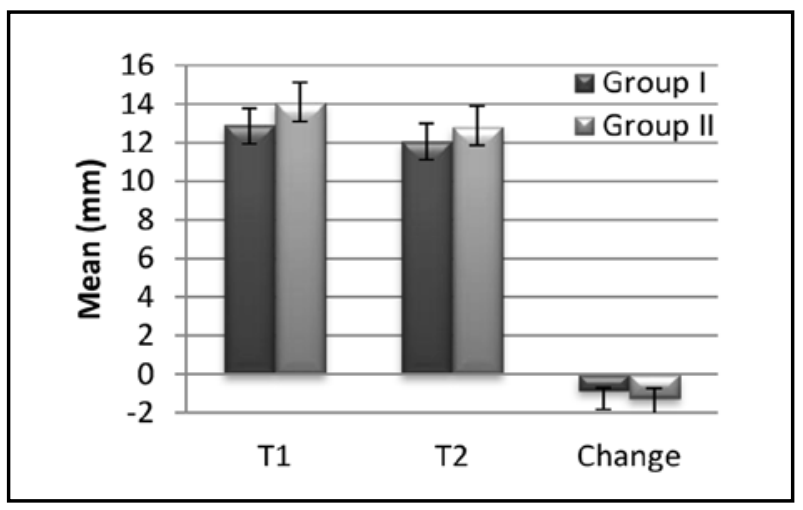

Fig. (3) Bar chart representing comparison of means of buccal crestal alveolar bone height ( $\mathrm{mm}$ ) of UR6 before (T1) $\&$ after (T2) intrusion between groups.

Table (4) Comparison between buccal crestal alveolar bone height ( $\mathrm{mm}$ ) of UL6 in both groups before (T1) \& after (T2) intrusion using Student's t-test and Mann-Whitney U test for comparing changes between groups.

\begin{tabular}{|c|c|c|c|c|c|c|c|c|}
\hline & \multicolumn{2}{|c|}{ Group I $(n=6)$} & \multicolumn{2}{|c|}{ Group II (n=7) } & \multicolumn{2}{|c|}{$95 \%$ CI for the difference } & \multirow{2}{*}{ p-value } & \multirow{2}{*}{ Sig. } \\
\hline & Mean & $S D$ & Mean & $S D$ & Lower bound & Upper bound & & \\
\hline $\mathrm{T} 1$ & 12.83 & 0.73 & 14.08 & 1.11 & -2.22 & -0.78 & $0.053^{\mathrm{a}}$ & $*$ \\
\hline $\mathrm{T} 2$ & 12.60 & 0.79 & 12.85 & 1.15 & -1.37 & 0.32 & $0.173^{\mathrm{a}}$ & NS \\
\hline Change & -0.23 & 0.12 & -1.23 & 0.52 & -0.03 & 0.65 & $0.087^{b}$ & NS \\
\hline
\end{tabular}

$S D=$ Standard Deviation, $n=$ number, $*=$ Significant $p \leq 0.05, N S=$ Non-Significant, $a=$ Student's $t$-test, $b=$ Mann- Whitney $U$ test, $p=$ probability level, Sig= Significance .

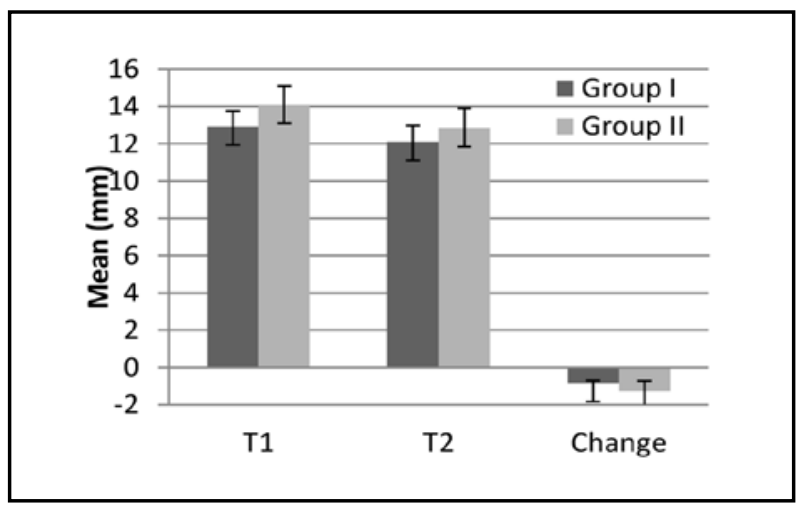

Fig. (4) Bar chart representing comparison of means of buccal crestal alveolar bone height $(\mathrm{mm})$ of UL6 between groups. 
Table (5): Comparison between M-D angulation of UR6 in both groups before (T1) \& after (T2) intrusion using Student's t-test and Mann-Whitney U test for comparison of changes between both groups.

\begin{tabular}{ccccccccc}
\hline & \multicolumn{2}{c}{ Group I $(\boldsymbol{n}=\mathbf{6})$} & \multicolumn{2}{c}{ Group II $(\boldsymbol{n}=7)$} & \multicolumn{2}{c}{$\mathbf{9 5 \%}$ CI for the difference } & p-value & Sig. \\
& Mean & $S D$ & Mean & $S D$ & Lower bound & Upper bound & \\
\hline T1 & 85.71 & 2.76 & 88.60 & 1.78 & -5.59 & -0.18 & $\mathbf{0 . 0 3 8}^{\mathbf{a}}$ & $*$ \\
T2 & 86.97 & 2.98 & 89.64 & 1.93 & -5.59 & 0.25 & $\mathbf{0 . 0 7 0}^{\mathbf{a}}$ & NS \\
Change & 1.26 & 0.45 & 1.04 & 0.32 & -0.24 & 0.67 & $\mathbf{0 . 4 4 0}$ & NS \\
\hline
\end{tabular}

$S D=$ Standard Deviation, $n=$ number,$*=$ Significant $p \leq 0.05, N S=$ Non-Significant $p>0.05, a=$ Student's $t$-test, $b=$ Mann-Whitney U test,$p=$ probability level, Sig= Significance.

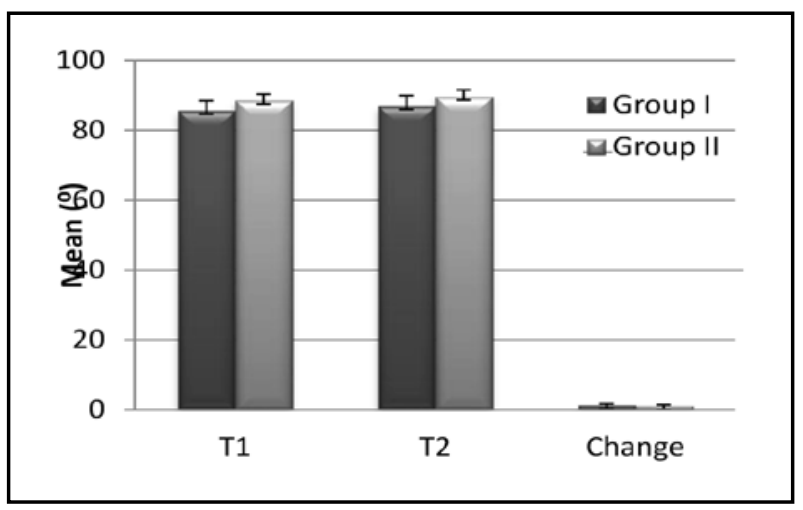

Fig. (5) Bar chart representing comparison of means of M-D crown angulation of UR6 before (T1) \& after (T2) intrusion between groups.

Table (6): Comparison between M-D angulation of UL6 before (T1) \& after (T2) intrusion in both groups using Student's t-test and Mann-Whitney U test for comparing changes between groups.

\begin{tabular}{|c|c|c|c|c|c|c|c|c|}
\hline & \multicolumn{2}{|c|}{ Group I (n=6) } & \multicolumn{2}{|c|}{ Group II (n=7) } & \multicolumn{2}{|c|}{$95 \%$ CI for the difference } & \multirow{2}{*}{ p-value } & \multirow{2}{*}{ Sig. } \\
\hline & Mean & $S D$ & Mean & $S D$ & Lower bound & Upper bound & & \\
\hline $\mathrm{T} 1$ & 86.21 & 2.73 & 88.56 & 1.68 & -4.98 & -0.19 & $0.035^{\mathrm{a}}$ & $*$ \\
\hline $\mathrm{T} 2$ & 86.99 & 2.88 & 89.84 & 1.91 & -4.96 & 0.35 & $0.080^{\mathrm{a}}$ & NS \\
\hline Change & 0.78 & 0.71 & 1.28 & 0.44 & -0.45 & 0.61 & $0.040^{b}$ & $*$ \\
\hline
\end{tabular}

$S D=$ Standard Deviation, $n=$ number, $*=$ Significant $p \leq 0.05, N S=$ Non-Significant $p>0.05, a=$ Student's $t$-test, $b=$ Mann-Whitney U test, $p=$ probability level, Sig $=$ Significance .

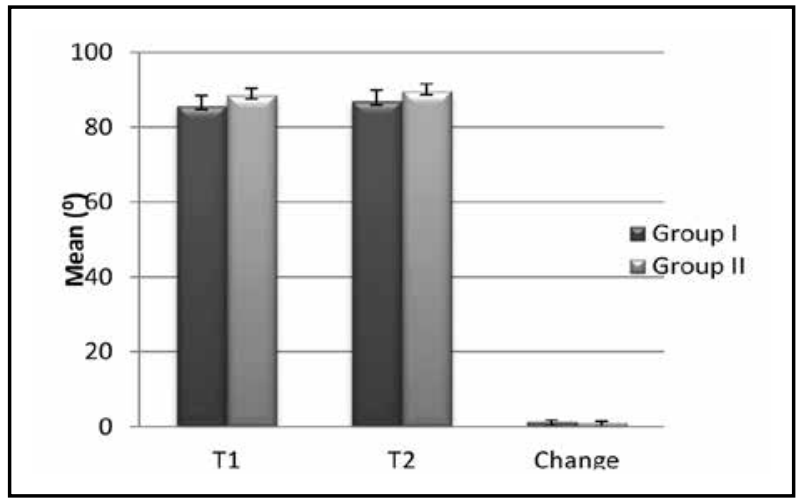

Fig. (6) Bar chart Line chart representing comparison of changes in mean M-D crown angulation of UL6 before (T1) \& after (T2) intrusion between both groups. 
Table (7): Comparison between B-P angulations of UR6 before (T1) \& after (T2) intrusion in both groups by Student's t-test and Mann-Whitney U test for comparing changes between both groups.

\begin{tabular}{|c|c|c|c|c|c|c|c|c|}
\hline & \multicolumn{2}{|c|}{ Group I $(n=6)$} & \multicolumn{2}{|c|}{ Group II (n=7) } & \multicolumn{2}{|c|}{$95 \%$ CI for the difference } & \multirow{2}{*}{ p-value } & \multirow{2}{*}{ Sig. } \\
\hline & Mean & $S D$ & Mean & $S D$ & Lower bound & Upper bound & & \\
\hline $\mathrm{T} 1$ & 87.06 & 3.13 & 86.51 & 2.89 & -2.97 & 4.05 & $0.742^{\mathrm{a}}$ & NS \\
\hline $\mathrm{T} 2$ & 88.84 & 2.95 & 88.81 & 3.09 & -3.48 & 3.54 & $0.986^{\mathrm{a}}$ & NS \\
\hline Change & 1.79 & 0.74 & 2.30 & 0.35 & -1.19 & 0.16 & $0.034^{b}$ & $*$ \\
\hline
\end{tabular}

$C I=$ Confidence Interval, $n=$ number,$N S=$ Non-Significant $p>0.05, *=$ Significant $p \leq 0.05, a=$ Student's $t$-test, $b=$ Mann-Whitney $U$ test,$p=$ probability level, Sig $=$ Significance. .

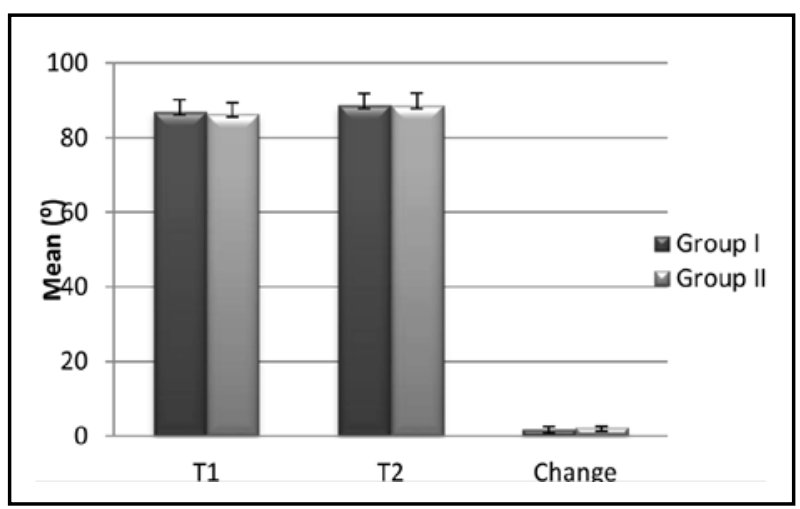

Fig. (7) Bar chart representing comparison of changes in B-P angulation of UR6 before (T1) \& after (T2) intrusion between groups.

Table (8): Comparison between B-P angulations of UL6 before (T1) \& after (T2) intrusion in both groups using Student's t-test and Mann-Whitney $U$ test for comparing changes between groups.

\begin{tabular}{|c|c|c|c|c|c|c|c|c|}
\hline & \multicolumn{2}{|c|}{ Group I $(n=6)$} & \multicolumn{2}{|c|}{ Group II (n=7) } & \multicolumn{2}{|c|}{$95 \%$ CI for the difference } & \multirow{2}{*}{ p-value } & \multirow{2}{*}{ Sig. } \\
\hline & Mean & $S D$ & Mean & $S D$ & Lower bound & Upper bound & & \\
\hline $\mathrm{T} 1$ & 87.12 & 3.12 & 86.11 & 2.59 & -2.98 & 4.05 & $0.702^{\mathrm{a}}$ & NS \\
\hline $\mathrm{T} 2$ & 89.01 & 2.86 & 89.01 & 3.05 & -3.18 & 3.34 & $0.886^{\mathrm{a}}$ & NS \\
\hline Change & 01.89 & 0.64 & 2.90 & 1.05 & -1.17 & 0.18 & $0.044^{b}$ & $*$ \\
\hline
\end{tabular}

$C I=$ Confidence Interval, $n=$ number, $N S=$ Non-Significant $p>0.05, *=$ Significant $p \leq 0.05, a=$ Student's $t$-test, $b=$ Mann-Whitney $U$ test, $p=$ probability level, Sig= Significance .

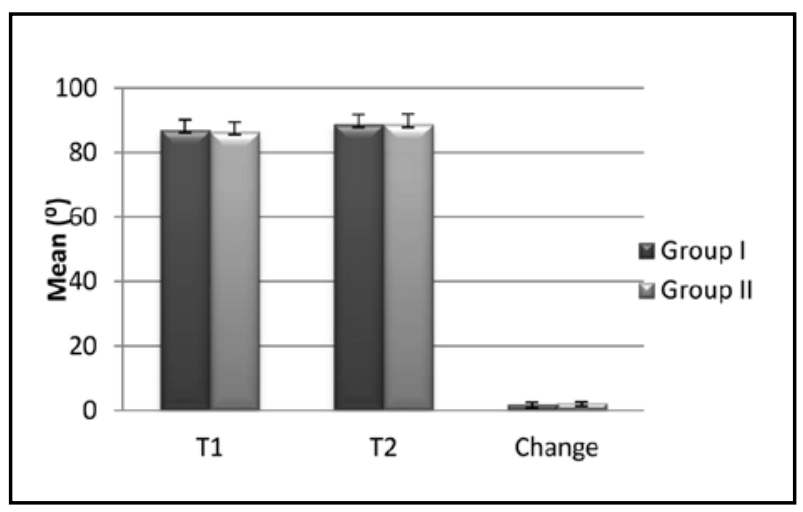

Fig. (8) Bar chart comparison of changes in B-P angulation of UL6 before (T1) \& after (T2) intrusion between groups 


\section{DISCUSSION}

Throughout the history of orthodontics, skeletal open bite has been considered one of the most difficult and challenging malocclusions, where combinations of skeletal, dental, and sometimes functional factors interact. It is often the outcome of a vertical growth pattern and increased maxillary posterior vertical height. Noteworthy, surgical treatment of SAOB malocclusion by conventional Le Fort 1 surgery was considered as the typical treatment or the first option for SAOB malocclusions ${ }^{(10)}$. Unfortunately, patient acceptance of this treatment modality was almost negative and not accepted by most of the current research patients. The second treatment option was intrusion of the posterior teeth to correct the anterior open bite. Therefore, molar intrusion considered to be the best treatment choice because it leads to an autorotation of the mandible in the counterclockwise direction, thus improving the long anterior facial height ${ }^{(11,12)}$. However, intrusion of posterior or anterior dentition is always difficult to achieve without the side effect of extrusion of the anchorage teeth ${ }^{(12-16)}$.

Temporary anchorage devices (TADs) were used to overcome this problem ${ }^{(22-28)}$. So the current study was performed using TADs; miniplates; to avoid these side effects of tooth borne anchorage during maxillary molar intrusion for management of skeletal anterior open bite. Moreover, this study was performed to compare between the efficiency of two surgical techniques, palatal and buccal corticotomies versus only buccal corticotomy, to assess maxillary molar intrusion during management of skeletal anterior open bite.

\section{Results' interpretation}

\section{Dento-alveolar height of maxillary $1^{\text {st }}$ permanent molars:}

In the current study; the maximum amount of achieved intrusion was $2.21 \mathrm{~mm}$ in patients who had both buccal and palatal corticotomies, and $2.02 \mathrm{~mm}$ in the group performed only buccal corticotomy in average time of $4 \pm 0.2$ months. These findings do not concur with those of previous case reports who obtained that intrusion in relatively longer periods of 6.5 months ${ }^{(21)}, 5.5$ months ${ }^{(15)}$, and 5.1months ${ }^{(35)}$. Moreover, most of these reports used only buccal corticotomies and 2D cephalometric radiographs for evaluation of intrusion that might explain such disagreement. The results of this study revealed that both miniplates and palatal mini-screws could be successfully used for molar intrusion. Statistical evaluation of these interventions revealed a significant amount of maxillary first right and left molars' intrusion $(1.55 \pm 0.71 \mathrm{~mm}$ and $1.11 \pm 0.71 \mathrm{~mm}$, respectively, in group I, as well as, $1.37 \pm 0.39 \mathrm{~mm}$, $1.50 \pm 0.46 \mathrm{~mm}$, respectively, in the group II). These results agree with several studies which showed comparable amounts of successful molar intrusion using TADs ${ }^{(13,21,35)}$.

In the current study, the intrusive forces where restricted only to the maxillary molars and the intrusive mechanics were initiated after completion of leveling and alignment using segmental fixed appliance. A previous study showed the amount of molar intrusion achieved could be related to the application of intrusive mechanics for both upper and lower molars by using full fixed appliances and application of intrusive mechanics on the whole posterior segment, upper and lower. This was undertaken to avoid, as much as possible, any additional variables that would be involved, if full fixed appliance and/or both upper and lower posterior segments were simultaneously intruded ${ }^{(35)}$.

\section{Bucco-palatal crown angulation of maxillary $1^{\text {st }}$ permanent molars:}

In the present $\mathrm{CBCT}$ study, both right and left maxillary first molars showed amount of buccal tipping that measured $1.79 \pm 0.74^{\circ}$ and $1.89 \pm 0.64^{\circ}$, respectively in group I. However, this buccal tipping was significantly greater in group II as measured $2.5 \pm 0.35^{\circ}$ and $2.9 \pm 0.52^{\circ}$, respectively. During intrusion of maxillary molars, a recent research ${ }^{(15)}$ avoided the use of trans-palatal arch (TPA) to 
eliminate the added variable of intrusive forces from the tongue being applied to a TPA. However, several case reports have utilized TPA to counteract the buccal intrusive force which was not available in the present study as previously described ${ }^{(21,26,27)}$.

Unfortunately, this observed amount of buccal tipping was unavoidable due to lack of TPA. In addition, the study design involved the application of palatal intrusive force via palatal mini-screws that made the use of TPA very difficult ${ }^{(36-38)}$.

It is important to note that, buccal tipping of the maxillary molars during intrusion could be another factor for lack of complete improvement of SAOB noticed in patients of the present study. The same note was observed in a previous investigation which revealed that buccal tipping of posterior maxillary segment was inevitable because of the location of the line of force in relation to the center of resistance of the segment. It has been reported that, tipping of buccal segment not only impaired posterior occlusion but also impeded successful elimination of the SAOB because of the interferences created between upper and lower teeth ${ }^{(10)}$.

However, reduction or curtail of buccal tipping of maxillary molars during intrusion was of major concern during performing the current study. Hence; it was the trigger to use mini-screws on the palatal sides for application of palatal intrusive force as well as to counteract the buccal tipping during application of buccal intrusive force as possible. Even though, it was reported that even with TADs as mini-screws located in the palate, it could be difficult to obtain a vector sum that passes through the center of resistance due to the anatomy of the palatal and buccal alveolar bone $e^{(20,28)}$.

\section{Mesio-distal crown angulation of maxillary molars:}

In the contemporary study, mesio-distal crown (M-D) angulations of maxillary right and left first permanent molars after intrusion were $86.97 \pm 2.98^{\circ}$ and $86.99 \pm 2.88^{\circ}$, respectively in group I. However, those were $89.64 \pm 1.93^{\circ}$ and $89.84 \pm 1.91^{\circ}$, respectively in group II. According to previous case reports ${ }^{(26,39)} \mathrm{M}-\mathrm{D}$ angulations reflected on the anterior overjet relation. It was reported that overjet was improved by distally inclining the mandibular molars using implants as orthodontic anchorage, and overbite was improved by extruding the anterior teeth ${ }^{(39)}$. Accordingly, this might be another important factor for mal- perfection of the anterior open bite closure of the present cases.

\section{Crestal alveolar bone height of maxillary first molars:}

The height of the crestal alveolar bone, measured in the current study, showed a significant decrease after intrusion. The amounts of decrease in group I were $0.83 \pm 0.12 \mathrm{~mm}$ and $0.23 \pm 0.13 \mathrm{~mm}$, respectively. That amounts were greater than the same measure in the cases with only buccal corticotomy which measured $1.25 \pm 0.52 \mathrm{~mm}$ and $1.23 \pm 0.52 \mathrm{~mm}$, respectively. These findings could be attributed to the buccal tipping that was previously mentioned in the existent discussion. The crestal alveolar bone height was rarely evaluated in previous studies concerning open bite correction; however, it was evaluated and found to be decreased by $1.89 \pm 0.59 \mathrm{~mm}$ after rapid maxillary expansion in a previous clinical trial study ${ }^{(40)}$.

\section{CONCLUSIONS}

On the basis of the current results and with the limitations of the present study, the following conclusions could be drawn:

1. The current corticotomy approaches were similarly effective for assistance of maxillary molar intrusion in cases of SAOB.

2. Although both interventions produced weighty amounts of maxillary molar intrusion, complete correction of SAOB was not achieved.

3. The posterior maxillary dento-alveolar heights diminished similarly in both corticotomy methods. 
4. The heights of buccal crestal alveolar bone showed nearly similar reductions in both groups.

5. Neither mesio-distal nor bucco-palatal angulations of maxillary first permanent molar crown revealed major changes in matching both approaches of intrusion.

6. Temporary anchorage devices could be effective for maxillary molar intrusion in cases of SAOB.

\section{REFERENCES}

1. Ross VA, Isaacson RJ, Germane N, Rubenstein LK. Influence of vertical growth pattern on faciolingual inclination and treatment mechanics. Am J Orthod. 1990; 98:422-9.

2. Sankey WL, Buschang PH, English J, Owen AH. Early treatment of vertical skeletal dysplasia: the hyperdivergent phenotype. Am J Orthod Dentofacial Orthop. 2000; 118:317-27.

3. Baccetti T, Franchi L, Schulz SO, McNamara JA. Treatment timing for an orthopedic approach to patients with increased vertical dimension. Am J Orthod Dentofacial Orthop. 2008; 133:58-64.

4. Firouz M, Zernik J,Nanda R. Dental and orthopedic effects of high-pull headgear in treatment of Class II, division 1 malocclusion. Am J Orthod Dentofacial Orthop. 1992; 102:197-205

5. Deberardinis M, Stretesky T, Sinha P, Nanda RS. Evaluation of the vertical holding appliance in treatment of high-angle patients. Am J Orthod Dentofacial Orthop. 2000; 117:700-5.

6. Stuani MB and Stuani AS. Modified Thurow appliance: a clinical alternative for correcting skeletal open bite. Am J Orthod Dentofacial Orthop. 2005; 128:118-25.

7. Cozza P, Baccetti T, Franchi L, Mucedero M. Comparison of 2 early treatment protocols for open-bite malocclusions. Am J Orthod Dentofacial Orthoped. 2007; 132:743-7.

8. Defraia E, Marinelli A, Baroni G, Franchi L, Baccetti T. Early orthodontic treatment of skeletal open-bite malocclusion with the open-bite bionator: a cephalometric study. Am J Orthod Dentofacial Orthop. 2007; 132:595-8.

9. Giuntini V, Franchi L, Baccetti T, Mucedero M, Cozza P. Dentoskeletal changes associated with fixed and removable appliances with a crib in open-bite patients in the mixed dentition. Am J Orthod Dentofacial Orthop. 2008; 133:77-80.
10. Erverdi N, Usmez S, Solak A. New generation open bite treatment with zygomatic anchorage. Angle Orthod. 2006; 76:519-62.

11. Vela-Hernández A, López-García R, García-Sanz V, Paredes-Gallardo V, Lasagabaster- Latorre F. Nonsurgical treatment of skeletal anterior open bite in adult patients: Posterior build- ups. Angle Orthodontist. 2017; 87:33-40.

12. Park YC, Lee HA, Choi NC, Kim DH. Open bite correction by intrusion of posterior teeth with mini-screws. Angle Orthod. 2008; 67:699-710.

13. Mehmet CA, Aynur A, Tayfun G, Sercan A, Banu OK. Enhanced effect of combined treatment with corticotomy and skeletal anchorage in open bite correction. J Oral Maxillofac Surg. 2009; 67:563-9.

14. Posterman B, Posterman L, Fisher R, Gornitsky M. The use of implants for the orthodontic correction of an open bite. Am J Orthod Dentofacial Orthop. 1995; 106:245-50.

15. Sherwood KH, Burch JG, Thompson WJ. Closing anterior open bites by intruding molars with titanium miniplate anchorage. Am J Orthod Dentofacial Orthop. 2002; 122:593-600.

16. Park HS, Kwon TG, Kwon OW. Treatment of open bite with mini-screw implant anchorage. Am J Orthod Dentofacial Orthop. 2004; 126:627-36.

17. Seres L, and Kocsis A. Closure of severe skeletal anterior open bite with zygomatic anchorage. J Craniofacial Surg. 2009; 20:478-82.

18. Harta TR, Cousleyb RJ, Fishmanc LS, Tallentsd RH. Dentoskeletal changes following mini- implant molar intrusion in anterior open bite patients. Angle Orthod. $2015 ; 85: 941-8$.

19. Hamdy MA. Effect of mini-screw implant supported intrusion on mandibular rotation in a group of children. Master thesis, Faculty of Oral and Dental Medicine, Cairo University, 2009.

20. Deguchi T, Kurosaka H, Oikawa H, Kuroda S, TakahashiI, Yamashiro T. Comparison of orthodontic treatment outcomes in adults with skeletal open bite between conventional edgewise treatment and implant-anchored orthodontics. Am J Orthod Dentofacial Orthop. 2011; 139:60-8

21. Tuncer C, Atac MS, Tuncer BB, Kaan E. Osteotomy assisted maxillary posterior impaction with miniplate anchorage. Angle Orthod. 2008; 78:737-44. 
22. Akay MC. Corticotomy and miniplate anchorage for treating severe anterior open-bite: Current clinical applications. A textbook of advanced oral and maxillofacial surgery, InTech publisher, 2013, p.714-59.

23. Leung MT, Lee TC, Rabie AB, Wong RW. Use of Miniscrews and Miniplates in Orthodontics. J Oral Maxillofac Surg. 2008; 66:1461-6.

24. Park JH, Tai K, Takagi M. Open-bite treatment using maxillary and mandibular miniplates. J Clin Orthod. 2015:398-408.

25. Ng J, Major PW, Flores-Mir C. True molar intrusion attained during orthodontic treatment: a systematic review. Am J Orthod Dentofacial Orthop. 2006; 130:709-14.

26. Park HS, Kwon OW, Sung JH. Nonextraction treatment of an open bite with mini-screw implant anchorage. Am J Orthod Dentofacial Orthop. 2006; 130:391-402.

27. Xun $C$, Zeng $X$, Wang $X$. Microscrew anchorage in skeletal anterior open bite treatment. Angle Orthod. 2007; 77:47-56.

28. Beycan K and Erverdi N. Anterior open-bite treatment by means of zygomatic miniplates: a case report. J Istanbul Univ Fac Dent 2017; 51:52-6.

29. Moon $\mathrm{CH}$ and Lee HS. Intrusion of overerupted molars by corticotomy and orthodontic skeletal anchorage. Angle Orthod. 2007;77:1119-25.

30. Grenga V and Bovi M. Corticotomy-enhanced intrusion of an overerupted molar using skeletal anchorage and ultrasonic surgery. J Clin Orthod. 2013; 17:50-5.

31. Akay MC,Aras A, Günbay T. Enhanced effect of combined treatment with corticotomy and skeletal anchorage in openbite correction. J Oral Maxillofac Surg. 2010; 67:563-9.

32. Cevidanes LHS, Styner MA Proffit WR. Image analysis and superimposition of 3-dimensional cone beam computed tomography models. Am J Orthod Dentofacial Orthop. 2006; 129:611-8.

33. Chen Y, Duan P, Meng, Y. Three-dimensional spiral computed tomographic imaging: a new approach to the diagnosis and treatment planning of impacted teeth. Am J Orthod Dentofacial Orthop. 2006; 130:112-6.

34. Deguchi T, Nasu M, Mukarami K, Yabuuchi T, Kamioka H, Takano-Yamamoto T. Quantitative evaluation of cortical bone thickness with computed tomographic scanning for orthodontic implants. Am J Orthod Dentofacial Orthop. 2006; 129:7-12.

35. Erverdi N, Keles A, Nanda R. The use of skeletal anchorage in open bite treatment: A cephalometric evaluation. Angle Orthod. 2004; 74:381-90.

36. Park YC, Lee SY, Kim DH, Jee SH. Intrusion of posterior teeth using mini-screw implants. Am J Orthod Dentofacial Orthop. 2003; 123:690-4.

37. Yao CJ, Lee J, Chen H, Chang ZJ, Chang H, Chen Y. Maxillary molar intrusion with fixed appliances and miniimplant anchorage studied in three dimensions. Angle Orthod. 2005; 75:754- 60.

38. Wilmes B, Nienkemper M, Ludwig B, Nanda R, Drescher D. Upper-molar intrusion using anterior palatal anchorage and the mousetrap appliance. J Clin Orthod. 2013:315-20.

39. Sakai Y, Kuroda S, Murshid S, Takano-Yamamoto T. Skeletal class III severe open bite treatment using implant anchorage. Angle Orthod. 2008; 78:157-66.

40. Brunetto M, Andriani J, Ribeiro G, Locks A, Correa M, Correab L. Three-dimensional assessment of buccal alveolar bone after rapid and slow maxillary expansion: A clinical trial study. Am J Orthod Dentofacial Orthop. 2013; 143:633-44. 